This journal is the official publication of Bangladesh Society of Physiologists (BSP)

Web URL: www.banglajol.info/index.php/JBSP

Abstracted /indexed in Index Copernicus, Director of Open Access Journal, Index Medicus for South East Asia Region, Google Scholar, 12OR, infobse index, Open J gate, Cite factor, Scientific indexing services

pISSN-1983-1213; e-ISSN-2219-7508

\title{
Article
}

Article information:
Received on $28 / 6 / 2018$
Accepted on $12 / 9 / 2018$
DOI:https://doi.org/10.3329/jbsp.v13i2.39477

Corresponding author:

Sharmin Nahar, Department of Physiology,

Dhaka Medical College, Dhaka.

E-mail: sharmin.physiol16@gmail.com

Cite this article:

Nahar S, Akhter QS. Effect of Curcuma longa (Turmeric) on serum creatine kinase-MB and troponin I in isoproterenol induced myocardial infarction in wistar albino rats

J Bangladesh Soc Physiol 2018;13(2): 47-53

This article is open access licensed under CC BY NC SA which allows readers copy, distribute, display, and perform the work and make derivative works based on it only for noncommercial purposes.

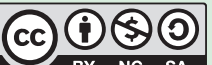

\section{Effect of Curcuma longa (Turmeric) on serum creatine kinase-MB and troponin I in isoproterenol induced myocardial infarction in wistar albino rats}

\author{
Sharmin Nahar ${ }^{1}$, Qazi Shamima Akhter ${ }^{1}$ \\ 1. Department of Physiology, Dhaka Medical College, Dhaka.
}

\section{Abstract}

Background: The prevalence of myocardial infarction (MI) is increasing day by day in Bangladesh due to socioeconomic transition. Spices and herbs are important source of remedy for various diseases in human. Curcuma longa suggested to be used as an indigenous medicine for the prevention and treatment of cardiovascular disease. Objective: To observe the effect of Curcuma longa in isoproterenol induced myocardial infarction in Wistar albino rats. Methods: This experimental study was carried out in the Department of Physiology, Dhaka Medical College, Dhaka during 2015. Twenty one Wistar albino male rats, weighing 100 to $150 \mathrm{~g}$ (initial body weight); aged 85 to 100 days were selected for the study. After acclimatization for 14 days, the rats were divided into BC (Baseline control group), ISP-TC (Isoproterenol treated control group) and CLP-ISPT (Curcuma longa pretreated and isoproterenol treated group). Each group consisted of 7 rats. After experiment, on the 10th day, final body weight was taken, rats were sacrificed and blood samples were collected from the heart. The heart was removed and weighed. Serum creatine kinase-MB (CK-MB) level was estimated by ELISA method and Troponin I (cTnI) level by AxSYM method. The statistical analysis was done by one way ANOVA and Bonferroni test as applicable. Results: In this study, the mean percent $(\%)$ change of body weight $(\mathrm{p}<0.01)$, mean serum CK-MB $(p<0.001)$ and $\mathrm{cTnI}(\mathrm{p}<0.001)$ levels were significantly higher but mean heart weight was non significantly higher in ISP-TC in comparison to those of BC. Again, the mean percent $(\%)$ change of body weight $(\mathrm{p}<0.01)$, mean heart weight 
$(\mathrm{p}<0.01)$, mean serum CK-MB $(\mathrm{p}<0.01)$ and $\mathrm{cTnI}(\mathrm{p}<0.001)$ levels were significantly lower in CLP-ISPT than those of ISP-TC group. Conclusion: From the results, it can be concluded that Curcuma longa may have cardioprotective effect.

Keyword: Cardioprotective, Curcuma longa, Isoproterenol, CK$\mathrm{MB}, \mathrm{cTnI}$.

Introduction

$\mathbf{M}$

yocardial infarction (MI) is a condition characterized by acute myocardial necrosis due to imbalance between coronary blood supply and myocardial metabolic demand ${ }^{1}$. A number of biochemical changes like, hyperlipidemia, lipid peroxidation, free radical injury, thrombosis occur in MI. As a result, qualitative and quantitative alterations of myocardium take place ${ }^{2}$. MI is the most common form of ischemic heart diseases (IHD) that affects a lot of populations in both developed and developing countries. Though there are several advancements in medical care and the availability of modern drugs, cardiovascular diseases (CVD) will be the leading cause of death globally by the year $2020^{3}$.

CVD are upcoming health issue in Bangladesh due to industrialization and socioeconomic development of the country. So, there is an urgent requirement to find out cardioprotective measures to manage the overall disease burden in Bangladesh ${ }^{4}$. Cardioprotective drugs (e.g. propranolol) are available in modern medicine. But prolong use of these drugs may produce some side effects like dyslipidemia, bradycardia, insomnia, light-headedness ${ }^{5,6}$.

Plant extracts consist of biologically important phytochemicals. Medicinal values of these phytochemical made it a potential resource for useful drugs and natural remedy for the prevention and treatment of human diseases ${ }^{7}$. Lycopene has cardioprotective effect against myocardial infarction which can be obtained by dietary consumption of tomato. It has no side effects. So, it can be consumed throughout the year as a dietary product ${ }^{8}$.

Isoproterenol (ISP) is a synthetic catecholamine and $\hat{a}$-adrenergic agonist that causes severe biochemical, physiological and histological changes in heart ${ }^{9}$. ISP is a recognized cardiotoxic agent which has the ability to damage myocardial cells ${ }^{10}$. Administration of high dose of ISP initiates lipid peroxidation and destroy membrane phospholipid resulting in myocardial cell injury by generating highly cytotoxic free radicals ${ }^{11}$. Serum creatin kinase (CK) and troponin I are highly sensitive biomarker for myocardial infarction. Myocardium contains high concentrations of these markers which release into the extracellular fluid when metabolically injured $^{12,13}$. Increased levels of these markers in the serum are due to loss of functional integrity and increased permeability of the cell membrane indicates myocardial necrosis ${ }^{14}$.

Curcuma longa (Turmeric) is a perennial herb, belongs to the family Zingiberaceae. It is widely cultivated in the tropical areas of South Asia, including Bangladesh, India, and China. The powder or paste forms of Curcuma longa are used as the main natural coloring and flavoring agents in the Indian subcontinent for the preparation of dishes. Since ancient time in Ayurvedic, folk and traditional Chinese medicine Curcuma longa has been used as an indigenous medicine against gastric, hepatic, gynecological and infectious 
diseases ${ }^{15-17}$. The most important chemical components of Curcuma longa are a group of compounds called curcuminoids, which include curcumin (diferuloylmethane), demethoxycurcumin and bisdemethoxycurcumin ${ }^{18}$. Among them most important active compound of Curcuma longa is curcumin. It is extracted from dry, powdered rhizome of Curcuma longa ${ }^{19}$. It has helpful effects on different forms of cardiovascular diseases like atherosclerosis, cardiac hypertrophy, hypertension and ischemia/ reperfusion ${ }^{20}$.

Some researchers observed that heart weight was significantly increased with relatively unchanged body weight and serum CK-MB and cTnI levels were significantly increased in rats treated with ISP $(85 \mathrm{mg} / \mathrm{kg}$ bw, subcutaneously) for 2 days. In cardiotoxic rats, the heart weight might be gained due to increased water content and edematous intramuscular space and the serum biomarkers level were higher due to myocardial damage ${ }^{21}$.

Some other investigators demonstrated the protective effects of Curcuma longa on ischemiareperfusion induced myocardial injury and their mechanisms in rats. Curcuma longa significantly decreased the biochemical markers of myocardial infarction, preserved myocardial antioxidant status and corrected the altered hemodynamic variables that were established by histopathological findings ${ }^{22}$.

Several other investigators also observed the cardioprotctive effects of Curcuma longa extracts against doxorubicin induced cardiotoxicity in rats. Here, Curcuma longa extracts significantly decreased the serum CK-MB level in Curcuma longa pretreated cardiotoxic rats ${ }^{23}$.

Again, some researchers suggested that curcumin treatment protects reperfusion injury induced cardiac dysfunction and myocardial injury in rats. They observed that curcumin pretreatment improved myocardial injury by decreasing serum levels of CK-MB and $\mathrm{cTnI}^{24}$. Therefore, the present study was aimed to assess the effect of Curcuma longa on serum CK-MB and cTnI in isoproterenol induced myocardial infarction in Wistar albino rats.

\section{Methods}

This experimental study was carried out in the Department of Physiology, Dhaka Medical College, Dhaka during 2015. The protocol of this study was approved by Ethical Review Committee of Dhaka Medical College. A total number of 21 Wistar albino male rats with aged 85 to 100 days and weighing 100 to 150 gm were selected for the study. The animals were purchased from the animal house of Department of Pharmacy, Jahangirnagar University, Savar, Dhaka. The animals were kept in metallic case in the animal house of Institute of Nutrition and Food Science, University of Dhaka. Before conducting the study, they were kept in a standard laboratory condition on a 12/12 hour light/dark cycle for acclimatization. Total study period was 23 consecutive days. During this period all the rats had free access to food and water. After acclimatization for 14 days, the rats were divided into BC (base line control group), ISP-TC (isoproterenol treated control group), CLP-ISPT (Curcuma longa pretreated and isoproterenol treated group). Each group consisted of 7 rats. Initial body weight of all the rats was measured on $1^{\text {st }}$ day of the experiment. All groups received basal diet for 9 consecutive days. In addition to basal diet, $\mathrm{BC}$ received normal saline orally ( $1 \mathrm{ml} / \mathrm{kg}$ body weight) using intragastric tube for 9 consecutive days and ISPTC received isoproterenol subcutaneously ( $150 \mathrm{mg} / \mathrm{kg}$ body weight/day) on $8^{\text {th }}$ and $9^{\text {th }}$ day. CLP-ISPT received ethanolic extract of Curcuma longa orally $(200 \mathrm{mg} / \mathrm{kg}$ body weight) for 9 consecutive days and isoproterenol subcutaneously (150mg/kg body weight/day) on 8 th and $9^{\text {th }}$ day. After the experiment, on the $10^{\text {th }}$ day all the rats were anaesthetized by $30 \%$ chloroform and sacrificed after taking final body weight. About $5 \mathrm{ml}$ of blood were collected from the heart of each rat. The blood was centrifuged and supernatant serum was collected and preserved in refrigerator for biochemical analysis. The heart 
was removed, washed in ice cold saline, wiped by tissue paper and weighed. The weight was measured by electronic weighing scale. Serum CK-MB level was estimated by ELISA method ${ }^{25}$ and serum cTnI was measured by AxSYM method $^{26}$. The results were compared among the different groups. The statistical analysis was done by one way ANOVA and Bonferroni test as applicable. $p$ value $<0.05$ was considered as significant.

Preparation of ethanolic extract of Curcuma longa: Rhizomes of Curcuma longa was purchased from local market of Dhaka. The rhizomes were cleaned, washed and dried in the sun light. Dried Curcuma longa were grinded in an electrical grinder. Then $250 \mathrm{gm}$ dried powder of Curcuma longa was extracted with $550 \mathrm{ml}$ of ethanol. The extract was evaporated in a rotator evaporator until a constant weight $(150 \mathrm{ml})$ was obtained ${ }^{23}$.

\section{Results}

The initial and final body weights of all the rats were almost similar and showed no statistically significant difference among the groups. The mean percent $(\%)$ change of body weight was significantly $(\mathrm{p}<0.01)$ higher in ISP-TC in comparison to that of $\mathrm{BC}$. Again, this change was significantly $(p<0.01)$ lower in CLP-ISPT in comparison to that of ISP-TC. But this change showed no statistically significant difference among BC and CLP-ISPT. (Table I)
The heart weight was higher in ISP-TC in comparison to that of $\mathrm{BC}$ which was not significant. Again, this level was significantly $(p<0.01)$ lower in CLP-ISPT in comparison to that of ISP-TC. But there was no significant difference between BC and CLP-ISPT. (Figure. 1)

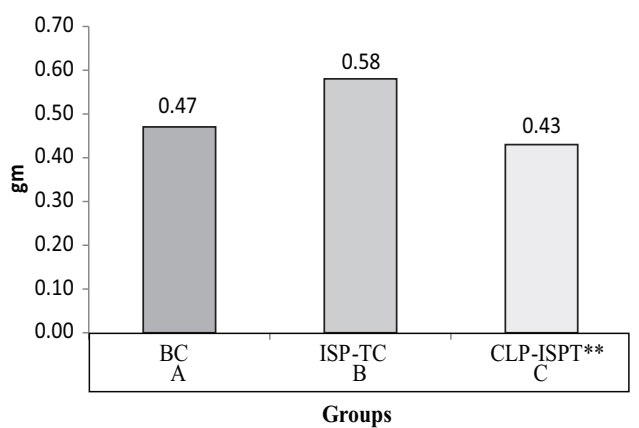

Figure 1: Heart weight in different groups of rats $(\mathrm{N}=21)$

Values are means \pm SD. Statistical analysis was done by one way ANOVA and then Bonferroni test. $\mathrm{N}=$ Number of rats. For heart weight $(* *=$ ISP-TC vs CLPISPT; $* *=\mathrm{p}<0.01) \mathrm{BC}=$ Baseline control group, ISP$\mathrm{TC}=$ Isoproterenol treated control group, CLP-ISPT $=$ Curcuma longa pretreated and Isoproterenol treated group.

The mean serum CK-MB and cTnI levels were significantly $(p<0.001)$ higher in ISP-TC in comparison to those of BC. Again, mean serum CK-MB $(\mathrm{p}<0.01)$ and $\mathrm{cTnI}(\mathrm{p}<0.001)$ levels were significantly lower in CLP-ISPT in comparison to those of ISP-TC. The mean serum CK-MB

Table I: Initial and final body weight and percent (\%) change of body weight in different groups of rats ( $\mathrm{N}=21)$

\begin{tabular}{lcccc}
\hline Parameter & \multicolumn{3}{c}{ Groups } \\
& & BC $(\mathrm{n}=7)$ & ISP-TC $(\mathrm{n}=7)$ & CLP-ISPT(n=7) \\
\hline Body weight (gm) & Initial body weight $(\mathrm{I})$ & $127.14 \pm 14.96$ & $127.14 \pm 11.12$ & $115.71 \pm 13.97$ \\
& Final body weight $(\mathrm{F})$ & $122.85 \pm 11.12$ & $112.85 \pm 11.12$ & $111.71 \pm 10.67$ \\
\% change $=[(\mathrm{F}-\mathrm{I}) / \mathrm{I} x 100]$ & $3.07 \pm 3.84$ & $11.22 \pm 4.04^{* *}$ & $3.16 \pm 3.79^{\# \#}$ \\
\hline
\end{tabular}

Values are means $\pm \mathrm{SD}$. Statistical analysis was done by one way ANOVA and then Bonferroni test. $\mathrm{N}=$ Number of rats. For $\%$ change of body weight $(* *=\mathrm{BC}$ vs ISP-TC; $* *=\mathrm{p}<0.01) \&$ (\#\#=ISP-TC vs CLP-ISPT; \#\#= $\mathrm{p}<0.01) . \mathrm{BC}=$ Baseline control group, ISP-TC $=$ Isoproterenol treated control group, CLP-ISPT $=$ Curcuma longa pretreated and Isoproterenol treated group. 
Table II: Serum CK-MB and Troponin-I levels in different groups of rats $(\mathrm{N}=21)$

\begin{tabular}{lccc}
\hline Parameter & \multicolumn{3}{c}{ Groups } \\
& $\mathrm{BC}(\mathrm{n}=7)$ & ISP-TC $(\mathrm{n}=7)$ & CLP-ISPT $(\mathrm{n}=7)$ \\
\hline CK-MB $(\mathrm{U} / \mathrm{L})$ & $12.84 \pm 2.80$ & $51.47 \pm 10.65^{* * *}$ & $33.87 \pm 6.81^{\text {\# }}$ \\
Troponin-I $(\mathrm{ng} / \mathrm{ml})$ & $1.48 \pm 0.28$ & $8.13 \pm 1.78^{* * *}$ & $4.77 \pm 1.26^{\# \# \#}$ \\
\hline
\end{tabular}

Values are means $\pm \mathrm{SD}$. Statistical analysis was done by one way ANOVA and then Bonferroni test. N=Number of rats. For CK-MB $(* * *=\mathrm{BC}$ vs ISP-TC; \#\#=ISP-TC vs CLP-ISPT) For Troponin I $(* * *=B C$ vs ISP-TC; \#\#\#=ISPTC vs CLP-ISPT $)(* * *=p<0.001 ; \# \#=p<0.01 ; \# \#=p<0.001)$ BC= Baseline control group, ISP-TC= Isoproterenol treated control group, CLP-ISPT $=$ Curcuma longa pretreated and Isoproterenol treated group.

$(\mathrm{p}<0.001)$ and $\mathrm{cTnI}(\mathrm{p}<0.01)$ levels were significantly higher in CLP-ISPT in comparison to that of BC. (Table II)

\section{Discussion}

The present study revealed that, the percent (\%) change of body weight from and heart weight were significantly higher with relatively unchanged body weight in isoproterenol treated control group in comparison to that of base line control group but these changes were significantly lower in Curcuma longa pretreated and isoproterenol treated group when compared with isoproterenol treated control group. Similar types of observation were made by some other researchers of different countries ${ }^{27}$.

In this study, serum CK-MB and cTnI levels were significantly higher in isoproterenol treated control group and than those of base line control group. Again these levels were significantly lower in Curcuma longa pretreated and isoproterenol treated group in comparison to those of isoproterenol treated control group. These findings are in consistent with those of some other research worker but they use curcumin instead of Curcuma longa ${ }^{23,28}$. The mean serum CK-MB and cTnI levels were significantly higher in Curcuma longa pretreated and isoproterenol treated group in comparison to that of base line control group. However, no published data are available to compare these findings.
It has been postulated that, subcutaneous injection of isoproterenol increase the percent (\%) change of body weight in experimental animals may be due to decreased intake of food and water. The heart weight was higher in isoproterenol induced rats may be due to increased water content, oedematous intramuscular space, extensive necrosis of myocardial fibers and infiltration of inflammatory cells in the damaged tissues. But pretreatment with curcumin significantly decreased the percent (\%) change of body weight and heart weight in isoproterenol induced rats and prevents myocardial cell injury 27,29 .

Some investigators suggested that increased level of oxidative stress and greater intensity of inflammatory response are the main characteristics of CVD which can be reduced by subsequent treatment of curcumin. It inhibits oxidative stress by decreasing superoxide generation, rising in catalase activity and reducing NADPH activity. It also reduces inflammatory response by reducing NF-kB activation and suppressing the gene expression of inflammatory cytokines, like TNF- $\alpha$, IL-1 and IL-6 ${ }^{20,30}$.

In the present study, isoproterenol induced myocardial infarction in rats was evidenced by increased percent (\%) change of body weight, increase heart weight and higher levels of serum CK-MB and cTnI levels. Again, decreased percent $(\%)$ change of body weight, heart weight 
and lower levels of these biochemical markers were observed in Curcuma longa pretreated and isoproterenol treated rats compared to isoproterenol treated control group. Therefore, it has been observed that Curcuma longa has cardioprotective effects which are most likely due to antioxidant and free radical scavenging activity.

\section{Conclusion}

From this study, it can be concluded that Curcuma longa (Turmeric) can prevent isoproterenol induced myocardial injury in rats. Thus, it can be used as home remedy that reduces premature death resulting from myocardial infarction.

\section{Conflict of interest- none}

Acknowledgement The authors acknowledge Professor Sheikh Nazrul Islam, Institute of Nutrition and Food Science, University of Dhaka, for his kind cooperation regarding laboratory facilities he provided.

\section{References}

1. Boudina S, Laclau MN, Tariosse L, Daret D, Gouverneur G. Alteration of mitochondrial function in a model of chronic ischemia in vivo in rat heart. Am. J. Physiol-Heart Cir. Physiol 2002; 282:H821-31.

2. Prathapan A, Rajamohan T. Antioxidant and antithrombotic activity of tender coconut water in experimental myocardial infarction. J. Food Biochem 2010; 35(5):1501-7.

3. Murray CJL, Lopez AD. Alternative projections of mortality and disability by cause 1990-2020: global burden of disease study. The Lancet 1997; 349 (9064):1498-504.

4. KMHSS Haque. Burden of Cardiovascular Diseases in Bangladesh. Cardiovasc. J 2011; 3(2): 120.

5. Naz N, Jahan N, Sultana N. Protective effect of peanut (Arachis hypogaea L) and its combination with propranolol on dyslipidemia in isoproterenol induced cardiotoxic rats. J Bangladesh Soc Physiol 2013; 8(2): 58-64.

6. Hoffman BB. Adrenoceptors antagonist drugs. In: Katzung BG, editor. Basic and Clinical
Pharmacology. America. The McGraw Hill Companies; 2001. P. 138-52.

7. Rizwan K, Zubair M, Rasool N, Riaz M, Zia-UlHaq M, De Feo V. Chemical and biological study of Agave attenuata. Int J Mol Sci. 2012; 13 (5): 644051 .

8. Parvin R, Akhter N. Protective effect of tomato against adrenaline induced myocardial infarction in rats. Bangladesh Med Res Counc Bull 2008; 34(3): 104-8.

9. Goyal S, Arora S, Bhatt TK, Das P, Sharma A, Kumari S, Arya DS. Modulation of PPAR ${ }^{3}$ by telmisartan protects the heart against myocardial infarction in experimental diabetes. Chem Biol Interact 2010; 185(1): 271-80.

10. Sharmila ST, Rajadurai M. Preventive effect of Bio-Aq on cardiac markers, lipids and membrane bound enzymes in isoproterenol induced myocardial infarction in rats. Asian J Pharm Clin Res. 2012; 5(2): 107-13.

11. Schinella GR, Tournier HA, Prieto JM, Mordujovich de Buschiazzo P, Rios JL. Antioxidant activity of anti-inflammatory plant extract. Life Sci 2002; 70(9):1023-33.

12. Farvin KHS, Anandan R, Kumar SH, Shiny KS, Sankar TV, Thankappan TK. Effect of squalene on tissue defense system in isoproterenol-induced myocardial infarction in rats. Pharmacol Res 2004; 50 (3): 231-6.

13. Upaganlawar A, Gandhi C, Balaraman R. Effect of green tea and vitamin $\mathrm{E}$ combination in isoproterenol induced myocardial infarction in rats. Plant Foods Hum Nutr 2009; 64 (1): 75-80.

14. Alam MN, Hossain MM, Rahman MM, Subhan N, Mamun MAA, Ulla A, Reza HM, Alam MA. Astaxanthin prevented oxidative stress in heart and kidneys of isoproterenol-administered aged rats. J Diet Suppl. 2018; 15(1):42-54.

15. Gupta SC, Sung B, Kim JH, Prasad S, Li S, Aggarwal BB. Multitargeting by turmeric, the golden spice: From kitchen to clinic. Molecular Nutr. and Food Res vol. 2013; 57(9): $1510-28$.

16. Karim MR, Haque A, Islam K, Ali N, Salam KA, ZA Saud, Hossain E, Fajol A, Akhand AA, Himeno S, Hossain K. Protective effects of the dietary supplementation of turmeric (Curcuma longa L.) on sodium arsenite-induced biochemical perturbation in mice. Bangladesh Med Res Counc Bull 2010; 36: $82-8$. 
17. Hasan M, Mahmud M. The contribution of turmeric research and development in the economy of Bangladesh: an ex-post analysis. Int. J. of Agricultural Res. Innovation and Tech. 2014; 4 (1): $1-10$.

18. Tayyem RF, Heath DD, Al-Delaimy WK, Rock CL. Curcumin content of turmeric and curry powders. Nutr Cancer. 2006; 55 (2): 126-31.

19. Maheshwari RK, Singh AK, Gaddipati J, Srimal RC. Multiple biological activities of curcumin: a short review. Life Sci. 2006; 78(18):2081-7.

20. Kapakos G,Youreva V, Srivastava AK. Cardiovascular protection by curcumin: molecular aspects. Indian J of Biochem \& Biophysics. 2012; 49(5):306-15.

21. Afroz R, Tanvir EM, KarimN, Hossain MS, Alam N, Gan SH, Khalil MI. Sundarban honey confers protection against isoproterenol induced myocardial infarction in wistar rats. BioMed Research International 2016; 2016 (Article ID 6437641):110 .

22. Mohanty IR, Arya DS, Dinda A, Joshi S, Talwar KK, Gupta SK. Protective effects of Curcuma longa on ischemia-reperfusion induced myocardial injuries and their mechanisms. Life Sci. 2004; 75(14): 1701- 14 .

23. El-Sayed EM, El-Azeem AS, Afify AA, Shabana $\mathrm{MH}$, Ahmed HH. Cardioprotective effects of Curcuma longa L. extracts against doxorubicininduced cardiotoxicity in rats. J Med Plants Res. 2010; 5(17): 4049-58.

24. Chen TH, Yang YC, Wang JC, Wang JJ. Curcumin treatment protects against renal ischemia and reperfusion injury induced cardiac dysfunction and myocardial injury. Transplant Proc. 2013; 45(10): 3546-9.

25. Wurzburg U, Hennrich N, Orth HD, Lang H, Prellwitz W, Neumeier D, Knedel M, Rick W. Quantitative determination of creatine kinase isoenzymes catalytic concentration in serum using immunological methods. J Clin Chem Clin Biochem.1977; 15(3):131-7.

26. Takahashi M, Lee L, Shi Q, Gawad Y, Jackowski G. Use of enzyme immunoassay for measurement of skeletal troponin I utilizing isoform-specific monoclonal antibodies. Clin Biochem. 1996; 29(4): 301- 8 .

27. Meziane MI, Djerdjouri B, Rimbaud S, Fanny C, Fortin D, Garnier A, Veksler V, Joubert F, Clapier RV. Catecholamine-induced cardiac myocardial dysfunction and mPTP opening: protective effect of curcumin. Am J Physiol Heart Circ Physiol 2011; 302 (3): $665-74$.

28. Yang $\mathrm{C}, \mathrm{Wu} \mathrm{K}$, Li SH, You Q. Protective effect of curcumin against cardiac dysfunction in sepsis rats. Pharm Biol. 2013; 51(4): 482-7.

29. Patel V, Upaganlawar A, Zalawadia R, Balaraman R. Cardioprotective effect of melatonin against isoproterenol induced myocardial infarction in rats: A biochemical, electrocardiographic and histoarchitectural evaluation. Eur J Pharmacol. 2010; 644 (1-3):160-8.

30. Anand P, Thomas SG, Kunnumakkara AB, Sundaram C, Harikumar KB, Sung B, Tharakan ST, Misra K, Priyadarsini IK, Rajasekharan KN, Aggarwal BB. Biological activities of curcumin and its analogues (Congeners) made by man and Mother Nature. Biochem Pharmacol 2008; 76(11): 1590611. 